\title{
ASSESSING PHYSICAL DISORDER IN URBAN NEIGHBORHOODS: RELIABILITY AND VALIDITY OF THE PARCEL MAINTENANCE OBSERVATION TOOL
}

\author{
Thomas M. Reischl, Allison M. Krusky, \\ Marc A. Zimmerman, Sophie M. Aiyer, \\ Daniel J. Kruger, Susan P. Franzen, \\ and Robert Lipton \\ University of Michigan School of Public Health
}

\begin{abstract}
Research on neighborhood factors that influence health and crime often use neighborhood measures of geographic areas such as census tracts, wards, and postal sectors. These administratively defined areas, however, may mask the heterogeneity of neighborhood influences. In response to calls for more specific measures, we tested the reliability and validity of the Parcel Maintenance Observation Tool (PMOT)-a new measure of physical disorder on property parcels. The results included baseline assessments of 6134 parcels in 2 urban neighborhoods, inter-correlations, inter-rater reliability, and tests of concurrent validity. Most of the measures had high or adequate inter-rater reliability. The PMOT measures differentiated between (a) parcels with occupied and unoccupied buildings and (b) vacant lots included in a property maintenance program and no-program vacant lots. The discussion focuses on potential uses of the PMOT for understanding the effects of neighborhood physical disorder and for evaluating health promotion and crime prevention programs. (C) 2015 Wiley Periodicals, Inc.
\end{abstract}

\footnotetext{
This research was supported by the Michigan Youth Violence Prevention Center Cooperative Agreement Number 5U01CE001957-02 (PI, Zimmerman) from the Centers for Disease Control and Prevention.

Please address correspondence to: Thomas M. Reischl, University of Michigan School of Public Health, 1415 Washington Heights, Ann Arbor, MI 48109-2029. E-mail: reischl@umich.edu
} 
Community researchers and social scientists have studied the effects of neighborhoods on life outcomes for decades (Leventhal \& Brooks-Gunn, 2000; Sampson et al., 2002). Several studies have focused on the effects of concentrated poverty in urban neighborhoods (Wilson, 1987) and have rejuvenated interest in social disorganization theory (Shaw \& McKay, 1942) to account for urban crime and other problems encountered in low income neighborhoods. Over the decades, there have been important advances in the theories and methods used to understand how neighborhoods influence crime (Hipp, 2007), childhood outcomes (Jenks \& Mayer, 1990; Leventhal \& Brooks-Gunn, 2000), health outcomes (Diez-Roux \& Mair, 2010; Picket \& Pearl, 2001), and mental health outcomes (Hill \& Maimon, 2013; Wandersman \& Nation, 1998).

Recent discussions of these studies have urged researchers to pay closer attention to the appropriate unit of analysis for studying neighborhood effects (Diez-Roux \& Mair, 2010; Hipp, 2007). Early studies often used administratively defined geographic areas such as census tracts, wards, and postal sectors as proxies for neighborhoods. Although using data for administratively defined areas has been convenient, these areas may not match residents' perceptions of their neighborhoods and may mask the geographical heterogeneity of important neighborhood influences.

In this study, we present a new observational measure of physical disorder for property parcels in urban neighborhoods. The parcel is the smallest, nonpoint areal unit available in urban geographic databases, but this new measure also allows researchers to aggregate measures for larger geographic units, including street segments, or any defined geographic area (e.g., Census tracts, postal areas). We also present data on the reliability and validity of this new measure. We argue that this new method provides more flexibility and specificity for assessing neighborhood disorder and will facilitate more specific hypothesis tests relating neighborhood features to health outcomes and crime. Finally, this new measure is a useful resource for outcome evaluations of neighborhood improvement interventions that prevent crime and promote health.

\section{Neighborhood Effects on Health and Crime}

After reviewing recent studies of how neighborhoods are related to health outcomes, Diez-Roux and Mair (2010) argued for greater specificity of geographic areas and neighborhood measures beyond economic status that are causally related to health outcomes. They noted that recent studies measured specific neighborhood physical features associated with physical activity (Saelens \& Handy, 2008), healthy eating (Larson et al., 2009), related outcomes of obesity (Papas, 2007), diabetes (Auchincloss et al., 2008), hypertension (Mujahid et al., 2008), and depressive symptoms (Dupere \& Perkins, 2007; Latkin \& Curry, 2003; Natsuaki et al., 2007; Ross \& Mirowksy, 2001). They also reviewed studies of more specific measures of social disorder that were consistently associated with depressive symptoms (Mair et al., 2008), but less consistently associated with physical health outcomes and health behaviors, suggesting the need for more specific neighborhood designations and neighborhood disorder measures (Diez Roux \& Mair, 2010).

Criminologists have also studied how neighborhood features create a context that may promote or deter crime. Similar to early public health studies, criminologists have found broad indicators of neighborhood disadvantage and diversity predicted higher crime rates (Kornhauser, 1978). Shaw and McKay (1942) hypothesized that disadvantaged, high crime neighborhoods suffered from the effects of persistent social disorganization that create a context favorable for crime and delinquency. An early test of Shaw and McKay's 
social disorganization theory indicated that crime victimization was higher in British neighborhoods with greater social disorganization (Sampson \& Groves, 1989).

Other researchers have focused on more specific social features and more complex hypotheses. In a study of Seattle neighborhoods, for example, Warner and Roundtree (1997) noted how the association of local friendship ties and crime rates might be mediated by a neighborhood's racial diversity and by the inclusion of criminals in social networks. In a study of Chicago neighborhoods, Sampson et al. (1997) found that the association of neighborhood disadvantage and violent crime was mediated by the neighborhood's collective efficacy.

Most of the early crime studies also used administratively defined geographic areas as proxies for neighborhoods (Sampson et al., 2002). A parallel set of crime studies, however, indicated that most urban crimes occur in very specific places such as a street corner, an address, a building, or a street segment (Eck \& Weisburd, 1995). Several researchers found a large proportion of urban crimes occur at a small number of specific places (Brantingham \& Brantingham, 1999; Sherman et al., 1989; Spelman, 1995; Weisburd \& Green, 1994, 2000). Weisburd et al. (2004) found over a 14-year period that $50 \%$ of Seattle's crime incidents occurred on $4 \%$ to $5 \%$ of the street segments. To understand why urban crimes cluster in specific places and why health outcomes are affected by neighborhood dynamics, there is a need to study neighborhood features at more specific units of analysis than administratively defined geographic units.

\section{Street Segments and Parcels}

Street segments, the area defined by facing sides of a street between street intersections, may be especially useful units of analysis for understanding how neighborhood features influence urban crime rates (Bursik \& Grasmick, 1993; Perkins et al., 1993; Taylor, 1997). In many cities, the residential block is where meaningful variation in social dynamics is related to the occurrence of crime. Taylor (1997) suggests that street segments operate as behavior settings (Barker, 1968), where residents are aware of routine activities, social roles, and behavior norms. The variation in these social dynamics across street segments may help explain why crimes cluster in specific places.

In addition, the physical features of street segments may influence the resident's perceptions and the crime-related social dynamics of street segments. Perkins et al. (1992), for example, noted that observed features in Baltimore denoting physical disorder, defensible spaces, and territoriality were correlated with resident's perceptions of neighborhood crime rates and social incivilities.

Although few researchers have studied the association between health outcomes and neighborhood features at the street segment or parcel levels, studies of street segments and parcels could allow more focused studies of causal mechanisms linking neighborhood features with health outcomes (Diez Roux \& Mair, 2010). Such studies, however, require specific measures of neighborhood features hypothesized to be associated with health and safety outcomes (Sampson \& Sampson \& Raudenbush, 1999).

Most researchers have assessed specific neighborhood features by either aggregating data from surveys of residents or directly observing social interactions and physical environments (Raudenbush \& Sampson, 1999). Resident surveys may best assess social features related to ongoing patterns of social connections, social norms, and social stressors, whereas direct observation methods may best assess physical features to avoid source bias that may lead to spurious results (Muhajid et al, 2007). This study focuses on the 
assessment of the physical features of neighborhoods and describes an observational assessment of physical features on property parcels.

We developed a new observational assessment procedure based, in part, on assessments developed for previous studies. Sampson and Sampson and Raudenbush (1999) used their systematic social observation ( $\mathrm{SSO}$ ) method that involved videotaping and coding indicators of physical and social disorder for a random sample of street segments in Chicago. They defined physical disorder as urban deterioration including graffiti, abandoned cars, broken windows, and trash. The final measures of physical disorder included dichotomous indicators of physical disorder on the street segment, including different types of litter, graffiti, and abandoned cars. The investigators, however, did not assess the maintenance of buildings and landscaping. The SSO was also limited to assessments of street segments and could not be used for assessing disorder at the parcel level.

In a recent study of Baltimore's street segments, researchers used the Neighborhood Inventory for Environmental Typology (NIfETy) to assess the incidence and prevalence of neighborhood features at the street segment level (Furr-Holden et al., 2008, 2010). The NIfETy included measures thought to be related to youth exposure to violence, alcohol, tobacco, and other drug activity, such as the physical layout of the street segment, types of structures, adult activity, youth activity, physical disorder and order, social disorder and order, and indicators of violence, alcohol, and other drug use activities. Their results provided evidence of these assessments' reliability and validity by noting predicted correlations with measures of neighborhood perceptions and with other observed health and safety outcomes. Like the SSO, the NIfETy was limited to measures of the street segment.

The Block Environment Inventory (BEI) and its adaptations assessed disorder for streets segments and for property parcels in New York City (Perkins et al., 1993), Baltimore (Perkins et al., 1992; Perkins \& Taylor, 1996), and Salt Lake City (Brown et al., 2004). The BEI was used to measure physical disorder on parcels and street segments, including ratings of litter and peeling paint as well as dichotomous (yes/no) observations of graffiti, broken windows or fixtures, cracked concrete, and poor lawn condition. The BEI also assessed physical features expressing territoriality and protection (occupancy, barriers, dogs, security alarm signs, gardens, and seating). These studies noted associations of observed physical disorder with police reports of crime and residents' fear of crime. These results justified the extension of this approach to include additional ratings and dichotomous observations of physical disorder on property parcels in the current study.

\section{Present Study}

To test more specific hypotheses regarding neighborhood physical disorder, more intensive assessments of physical disorder for property parcels are needed. Assessing physical disorder and order at the level of the property parcel has distinct advantages including (a) accounting for variation in physical disorder/order at the smallest available geographic unit of analysis and (b) studying changes in neighborhood physical disorder/order associated with interventions with individual property owners. A property parcel is a contiguous lot or tract of land with defined borders registered with a recognized government agency and includes affixed structures, anything below the land, and anything growing on the land. The widespread practice of defining property boundaries and property ownership rights/responsibilities is a legacy of English common law (Bethell, 1998).

In the United States, the rights and responsibilities of parcel owners are defined by state laws and local ordinances and often establish infractions related to maintenance of structures and landscaping on parcels. Parcel owners are legally responsible for 
maintaining buildings and lots; interventions to address physical disorder will likely require the involvement of property owners.

In the present study, we describe the development of the Parcel Maintenance Observation Tool (PMOT) and preliminary data assessing its reliability and validity. The PMOT guides a trained observer to assess a variety of physical features of individual parcels including the type of parcel (e.g., residential, church, vacant lot, vegetable garden). The PMOT also includes assessments of visible physical disorder and order such as building maintenance and appearance, landscaping and mowing, and litter and trash. The PMOT includes observations similar to those used in previously published measures (e.g., SSO, NIfETy, and BEI), but also includes new measures than enhance the specificity of physical disorder assessment. These new measures include dichotomous (yes/no) observations of fire damage, discarded appliances, onsite construction, and home adornments. The PMOT also includes new multipoint ratings of litter and trash, building protective surfaces, building structural elements, landscaping maintenance, and lawn maintenance. Finally, the PMOT includes an observation of the primary purpose of the parcel with 15 distinct parcel functions (listed below).

The primary research questions focused on the reliability of the observational measures, the observed base rates of the measures, patterns of correlation among the measures, and recommendations for combining single items into measurement scales with adequate internal consistency.

We also studied the concurrent validity of the PMOT measures. Cronbach and Meehl (1955) distinguished concurrent validity from other types of measurement validity as the degree to which a measure predicts a criterion assessed at the same time. We hypothesized that PMOT measures will distinguish expected differences between (a) parcels with occupied and unoccupied buildings and (b) vacant lots in Genesee County Land Bank's Clean \& Green program and vacant lots not in this program. The Clean \& Green program engaged and supported community organizations to maintain tax-foreclosed vacant lots acquired by Genesee County. The community organizations agreed to mow the vacant lots at least once every 3 weeks, remove debris, and engage youth in their efforts. We expected that the Clean \& Green program vacant lots would have less litter/trash and better mowing maintenance than no-program vacant lots.

\section{METHODS}

This study occurred in Flint, Michigan. Flint is an industrial city and the county seat of Genesee County whose population has grown and declined during the 20th century with the manufacturing capacity of the city's largest employer, General Motors (GM). In 1970, GM employed an estimated 80000 workers at Flint area plants. GM and affiliated industries currently employ around 15000 area workers. As these manufacturing jobs left the area, so did a significant portion of Flint's population, declining 48\% from 196940 in 1970 to 102434 in 2010 (US Census, 2012). The city of Flint also has recently experienced higher unemployment rates than most metropolitan areas in the United States (U.S. Bureau of Labor Statistics, 2013). One recent compilation of FBI crime statistics noted that Flint had the second highest violent crime rate among American cities (Morgan et al., 2013).

The data collection occurred in two residential neighborhoods within the city of Flint. One neighborhood was the intervention site for youth violence prevention programs associated with the Michigan Youth Violence Prevention Center (Morrel-Samuels et al., 2013) and the other neighborhood was a comparison site 1.6 miles north of the 
intervention neighborhood. The two neighborhoods studied were dominated by older single-family homes on grids of north-south and east-west street segments forming city blocks. U.S. Census data indicated the two areas had high percentages of lower income, African American residents.

\section{PMOT}

The PMOT had four sections including (a) parcel identification data, (b) parcel type, (c) visible features, and (d) parcel ratings. The parcel identification data were populated by the county's property tax database and include data fields about each parcel's street address, zip code, registered parcel number, and block group number. The parcel type was a single item requiring the observer to choose 1 of 16 general categories describing the primary purpose of the parcel; the categories included residential (two categories), commercial (three categories), industrial, schools, public park, religious organization, government organization, civic organization, public utility, parking lot, produce garden, vacant lot, and street access.

The visible features section included 10 physical features that are visible from street in front of the property including evidence of occupancy, broken/boarded windows, broken/boarded doors, graffiti, fire damage, discarded vehicles, discarded appliance/furniture, ongoing construction, vegetable garden, and adornments (e.g., ornaments, decorations, flower baskets, flags located on the home). The parcel ratings included five ratings that require observers to judge the quality of property maintenance for five dimensions: (a) the amount of litter and trash (5-point rating: no litter to more than a tall kitchen bag of litter); (b) the condition of protective surfaces (e.g., siding, roof) on permanent buildings (7-point rating: not salvageable to appealing decor); (c) the condition of exposed structural elements (e.g., rafters, concrete foundation) on permanent buildings (5-point rating: not salvageable to well maintained); (d) landscaping (4-point rating: overgrown to prime condition); and (e) mowing/weeding (7-point rating: no maintenance to prime condition).

The observations of specific visible features and the parcel ratings were contingent on what was present on the parcel. For instance, noting broken windows or rating protective surfaces occurred only if there is a permanent building on the parcel. If there was no building, these observations were coded as missing. Similarly, ratings of landscaping maintenance only occurred if there was evidence of decorative plantings or landscaping elements on the parcel. Finally, mowing/weeding ratings were completed only if there were open grassy areas.

\section{PMOT Observer Training and Reliability Testing Methods}

Six observers attended two didactic training sessions (totaling 6 hours) covering background information on the research project, safety training, parcel map reading, parcel observations, and completing the PMOT. Observers received an instructional manual with written instructions for completing the PMOT, including decision trees for completing the parcel ratings. The project supervisor demonstrated how to use the decision trees while showing photos of parcels as examples for specific ratings. The observers practiced using the PMOT tool while viewing additional parcel photographs. After the didactic training sessions, the property observers practiced assessing parcels using the PMOT for 2 hours in Flint neighborhoods. The observers reconvened after the practice assessments and discussed their observations and ratings. 
Table 1. Average (and Range) Percent Agreement and Correlations With Standard Ratings of PMOT Visible Features and for Parcel Ratings

\begin{tabular}{lcc}
\hline & $\begin{array}{c}\text { Initial reliability } \\
\text { test }(129 \text { Parcels })\end{array}$ & $\begin{array}{c}\text { Second reliability } \\
\text { test }(103 \text { Parcels })\end{array}$ \\
\cline { 2 - 3 } Visible features & Percent agreement & Percent agreement \\
\hline Fire damage & $100 \%(100 \%$ to $100 \%)$ & $100 \%(100 \%$ to $100 \%)$ \\
Graffiti & $97.2 \%(96.5 \%$ to $97.9 \%)$ & $99.0 \%(98.5 \%$ to $99.2 \%)$ \\
Discarded vehicles & $98.6 \%(98.3 \%$ to $98.8 \%)$ & $96.4 \%(95.4 \%$ to $96.9 \%)$ \\
Discarded appliances and & $99.4 \%(99.2 \%$ to $99.6 \%)$ & $99.0 \%(98.6 \%$ to $99.4 \%)$ \\
furniture & & $96.4 \%(95.2 \%$ to $97.1 \%)$ \\
Broken windows & $97.1 \%(95.4 \%$ to $97.7 \%)$ & $94.6 \%(92.7 \%$ to $95.8 \%)$ \\
Boarded windows & $97.1 \%(96.9 \%$ to $97.5 \%)$ & $96.0 \%(93.2 \%$ to $97.1 \%)$ \\
Broken \& boarded doors & $97.2 \%(96.1 \%$ to $98.4 \%)$ & $89.3 \%(86.7 \%$ to $91.7 \%)$ \\
Property occupied & $93.4 \%(92.1 \%$ to $94.8 \%)$ & $100 \%(100 \%$ to $100 \%)$ \\
Construction in progress & $92.7 \%(88.4 \%$ to $98.4 \%)$ & $85.1 \%(77.1 \%$ to $88.3 \%)$ \\
Adornments & $93.7 \%(90.1 \%$ to $95.4 \%)$ & $99.0 \%(99.0 \%$ to $99.0 \%)$ \\
Vegetable gardens & $100 \%(100 \%$ to $100 \%)$ & Inter-rater correlation \\
\hline Parcel ratings & Inter-rater correlation & $.79(.73$ to .83$)$ \\
\hline Landscaping & $.55(.40$ to .65$)$ & $.83(.80$ to .85$)$ \\
Mowing & $.59(.53$ to .65$)$ & $.93(.91$ to .94$)$ \\
Protective surfaces & $.84(.72$ to .89$)$ & $.93(.91$ to .94$)$ \\
Structural elements & $.87(.74$ to .91$)$ & $.58(.52$ to .63$)$ \\
Litter \& trash & $.60(.48$ to .67$)$ &
\end{tabular}

Note. PMOT $=$ Parcel Maintenance Observation Tool. Reliability statistics for six trained observers based on agreement and correlation with reconciled observations of two expert observers (i.e., standard ratings).

After completing the didactic training and practice ratings, all six observers completed an initial reliability test. The trained observers completed the PMOT for 129 parcels. We compared the six trained observers' PMOT recorded observations to standard observations established by two expert observers who had completed and reconciled PMOT observations of the same 129 parcels. The project supervisor reviewed the initial reliability results with each of the trained observers and provided written individual feedback. After discussing the results of the initial reliability tests in a 3-hour follow-up training session, the six trained observers completed PMOT observations of 103 new parcels for a second reliability test, comparing their observations with standard observations established by reconciling recorded observations of the same two expert observers. The results of the two reliability tests are provided below in Table 1.

\section{Data Collection Procedures}

After the training and reliability testing, pairs of observers walked on opposite sides of the same street while completing the PMOT protocol for parcels on their side; one observer assessed each parcel. Using street and parcel maps, the observer first judged the location of parcel boundaries and then completed the PMOT form based on observations from the front of the parcel. Each assessment typically took less than 5 minutes to complete. The trained observers completed PMOT forms for 6,134 parcels. Most of the observed parcel types were either small residences or vacant lots (see base rates below). Over half of these parcels $(3,669 ; 59.8 \%)$ had a permanent building. Less than half the parcels 
$(2,435 ; 39.7 \%)$ had evidence of landscaping, but nearly all the parcels $(5,973 ; 97.4 \%)$ had open grassy areas.

\section{Validity Testing Methods}

The comparisons of parcels with occupied and unoccupied buildings were based on the observers' judgment about evidence of occupancy on the parcel. Comparing vacant parcels (with no buildings) in the Clean \& Green lot maintenance program with other vacant parcels required coding of parcels as a Clean \& Green lot from the Genesee County Land Bank's program database. We conducted comparisons of these groups of parcels using (a) multiobservation scales with adequate internal consistency and (b) single observation items. The development of the multiobservation scales were based on internal consistency analyses described below.

\section{RESULTS}

\section{Reliability Analyses}

Parcel type. The six observers demonstrated a high level of agreement with the standard observation of the parcel type category. The average percent agreement among the six observers was $95.2 \%$ (range: $82.3 \%$ to $97.6 \%$ ) at the initial reliability test. The average percent agreement improved to $98.0 \%$ (range: $96.1 \%$ to $100 \%$ ) at the second reliability test after follow-up training.

Visible features. The six observers also demonstrated high levels of inter-rater reliability when observing the presence or absence of visible feature. The average percent agreement with standard observations was above $85 \%$ for all visible features at the initial and the second reliability tests. The range of percent agreement ranges in Table 1 indicates that all observers agreed with the standard observations at least $77 \%$ of the time.

Parcel ratings. We also found high levels of correlation between the trained observers and the standard observations for the multipoint observation ratings of the quality of building and land maintenance, especially for the second reliability test (see Table 1). The highest correlations between the observers' and the standard observations were for ratings of the protective surfaces and structural elements of buildings. The average reliability of the trained observers improved at the second reliability test after follow-up training for all multipoint ratings except the rating of litter and trash on the parcel.

\section{Base Rates, Internal Consistency, and Scale Development}

The base rates for the parcel type observation were dependent on the parcels observed in the two primarily residential neighborhoods in this study. Over half of the parcels were residential properties $(56.7 \%)$ and over one third of the parcels were vacant lots $(38.0 \%)$. Fewer than $3 \%$ of the parcels were commercial properties. None of the remaining 14 parcel types accounted for more than one percent of the assessed parcels. There were no industrial parcels observed.

The base rates for the other PMOT measures (visible features, parcel ratings) were also dependent on the parcels observed. The data in Table 2 indicate that less than 


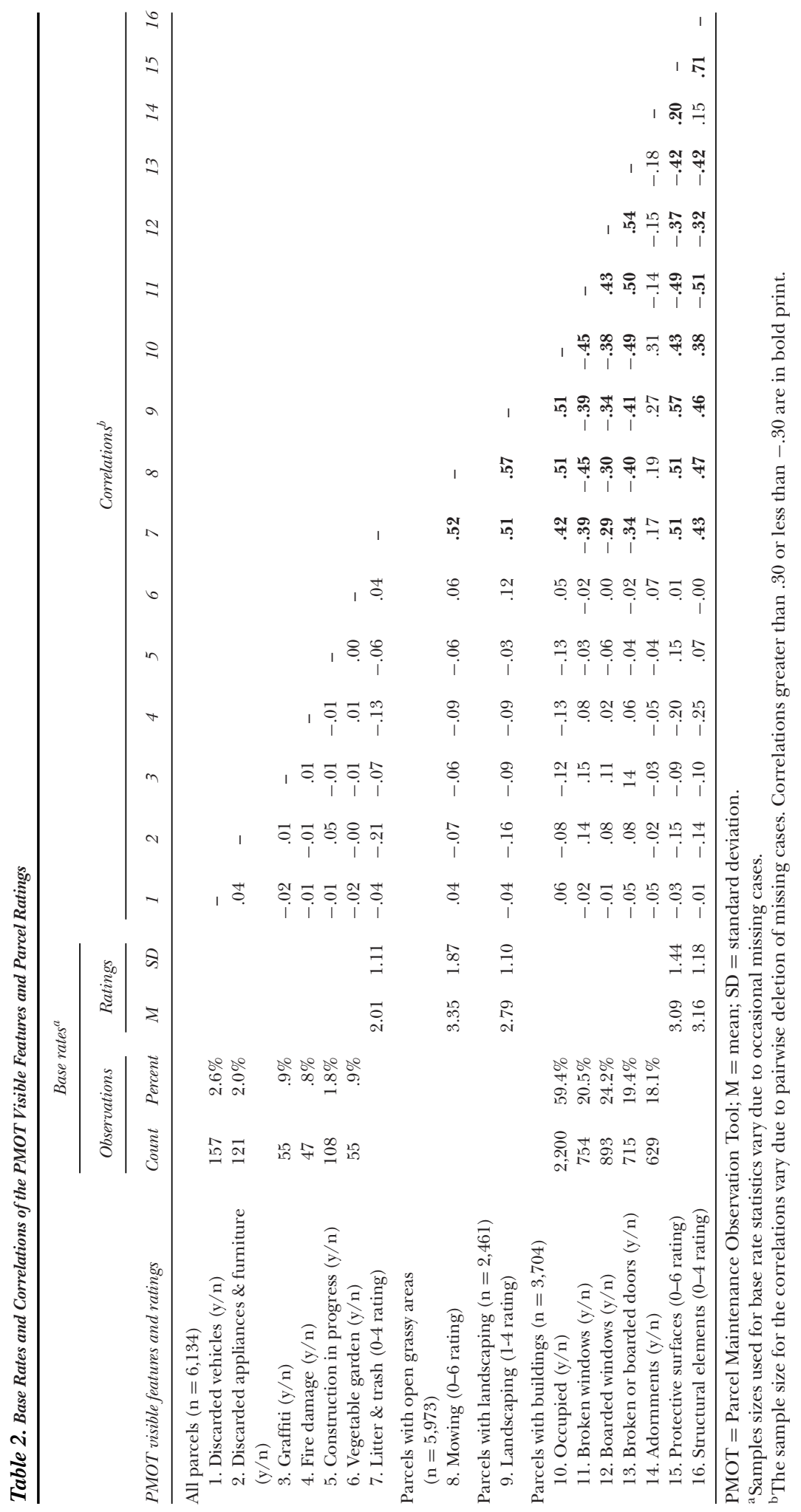


three percent of parcels had large debris (e.g., vehicles, appliances, and furniture) and other physical features suggesting disorder (e.g., graffiti, fire damage). We also found low base rates of construction and vegetable gardens. The base rates for broken or boarded windows and doors were higher (between $19 \%$ and $25 \%$ of the observed parcels with buildings). Evidence of building occupancy was observed in fewer than $60 \%$ of the buildings. Building adornments were noted on $18 \%$ of the buildings.

The baseline average ratings of litter and trash, landscaping maintenance, and mowing maintenance were in the middle of their respective scales with standard deviations indicating adequate variation. The same was true of the ratings of the building's protective surfaces and structural elements. These base rates suggested no measurement ceiling or floor effects and the potential for documenting changes over time.

The pattern of correlations among the 16 observed variables (see Table 2) suggest that the physical features with low base rates also had low correlations with the other observations and ratings. Nearly all the correlations among the ten variables with adequate base rates were above .30 or below -.30 .

In our attempt to identify internally consistent multi-item parcel maintenance scales, we combined nine of the correlated variables and computed a General Parcel Maintenance scale with a high level of internal consistency $($ alpha $=.80)$. We omitted the occupancy observation because we believed occupancy alone was not a direct indicator of maintenance effort and we used the occupancy observation as a predictor variable in our validity analyses. This nine-item scale could only be used on parcels with a building, an open grassy area, and evidence of landscaping. Thus, in our sample of 6,134 parcels, only 2,035 parcels (33\%) met these criteria.

We also computed a Building Maintenance scale with the six features pertaining to buildings (broken windows, boarded windows, broken/boarded doors, adornments, protective surfaces, and structural elements) for the parcels with buildings ( $57 \%$ of our sample). The internal consistency (alpha) of this scale was .72. We also computed a Lot Maintenance scale using the three remaining observations about the mowing, landscaping, and litter/trash on the parcel for parcels with evidence of landscaping and open grassy areas ( $40 \%$ of our sample). The alpha for this three-item scale was .77. By combining the mowing and litter/trash rating into a two-item Lawn Maintenance scale $(r=.52)$, we assessed parcels with open grassy areas (parcels $97 \%$ of our sample). We created standardized scores for each item before computing each of these scale scores.

\section{Concurrent Validity Analyses}

Comparing occupied and unoccupied buildings. As hypothesized, the PMOT measures detected meaningful differences between parcels with occupied buildings and unoccupied buildings. Parcels with occupied buildings were better maintained than parcels with unoccupied buildings. The results in Table 3 note that unoccupied parcels were 3 to 11 times more likely to have visible features indicating disorder (e.g., broken windows, broken/boarded doors, discarded appliances/furniture, and graffiti) than the occupied parcels. Occupied parcels, however, were twice as likely to have an abandoned vehicle. Occupied parcels had a much higher likelihood of having adornments and vegetable gardens. Similar differences were found on the parcel ratings of building and lot maintenance (see Table 4). The difference in means between the unoccupied and occupied parcels was often a full standard deviation or more for all five maintenance ratings. 
Table 3. The Percent of Unoccupied and Occupied Buildings With PMOT Visible Features $(n=3704)$

\begin{tabular}{|c|c|c|c|}
\hline \multirow[b]{2}{*}{ Visible features } & \multicolumn{2}{|c|}{ Occupancy } & \multirow[b]{2}{*}{$x^{2}$} \\
\hline & $\begin{array}{l}\text { Unoccupied } \\
(n=1504)\end{array}$ & $\begin{array}{c}\text { Occupied } \\
(n=2200)\end{array}$ & \\
\hline Broken windows & $42.5 \%$ & $5.7 \%$ & $734.38^{* * *}$ \\
\hline Boarded windows & $44.3 \%$ & $10.7 \%$ & $542.73^{* * *}$ \\
\hline Broken or boarded doors & $43.1 \%$ & $3.5 \%$ & $886.40^{* * *}$ \\
\hline Discarded vehicle & $2.0 \%$ & $4.2 \%$ & $13.87^{* * * *}$ \\
\hline Discarded appliances and furniture & $4.6 \%$ & $1.7 \%$ & $26.06^{* * *}$ \\
\hline Graffiti & $3.3 \%$ & $.3 \%$ & $54.42^{* * *}$ \\
\hline Fire damage & $2.9 \%$ & $0.0 \%$ & $60.25^{* * * *}$ \\
\hline Construction on site & $4.3 \%$ & $.6 \%$ & $58.93^{* * *}$ \\
\hline Adornments & $3.5 \%$ & $27.6 \%$ & $323.27^{* * *}$ \\
\hline Vegetable garden & $.1 \%$ & $.9 \%$ & $10.57^{* *}$ \\
\hline
\end{tabular}

Note. PMOT $=$ Parcel Maintenance Observation Tool. The sample size varied (from 3474 to 3704 ) due to missing data in some of the visible features.

$* * \mathrm{p}<.01, * * * \mathrm{p}<.001$

Table 4. Means and Standard Deviations for PMOT Parcel Ratings of Unoccupied and Occupied Buildings

\begin{tabular}{|c|c|c|c|c|c|c|}
\hline & \multicolumn{4}{|c|}{ Occupancy } & \multirow[b]{3}{*}{$d f$} & \multirow[b]{3}{*}{$F$} \\
\hline & \multicolumn{2}{|c|}{ Unoccupied } & \multicolumn{2}{|c|}{ Occupied } & & \\
\hline & $M$ & $S D$ & $M$ & $S D$ & & \\
\hline \multicolumn{7}{|l|}{ Parcel ratings } \\
\hline Litter and trash & 1.44 & 1.20 & 2.45 & .99 & 1,3702 & $780.93^{* * *}$ \\
\hline Landscaping & 1.89 & 1.01 & 3.13 & .92 & 1,2137 & $764.04^{* * *}$ \\
\hline Mowing & 2.63 & 1.92 & 4.40 & 1.02 & 1,3615 & $1295.62^{* * *}$ \\
\hline Protective surfaces & 2.34 & 1.56 & 3.60 & 1.08 & 1,3702 & $835.08^{* * * *}$ \\
\hline Structural elements & 2.63 & 1.41 & 3.53 & .81 & 1,3700 & $604.20^{\text {**** }}$ \\
\hline \multicolumn{7}{|l|}{ Multi-item scales } \\
\hline General maintenance & -.48 & .69 & .40 & .40 & 1,2033 & $1265.23^{* * *}$ \\
\hline Building maintenance & -.52 & .72 & .33 & .41 & 1,3471 & $1945.17^{* * *}$ \\
\hline Lot maintenance & -.48 & .82 & .46 & .57 & 1,2114 & $894.51^{* * *}$ \\
\hline Lawn maintenance & -.46 & .91 & .48 & .57 & 1,3615 & $1387.94^{* * * *}$ \\
\hline
\end{tabular}

Note. PMOT $=$ Parcel Maintenance Observation Tool; $\mathrm{M}=$ mean; $\mathrm{SD}=$ standard deviation; $\mathrm{df}=$ degree of freedom. $* * * \mathrm{p}<.001$.

Comparing Clean $\mathcal{E}$ Green program and no-program vacant lots. The concurrent validity of the PMOT measures was partially supported by comparing vacant lots in the Genesee County Land Bank's Clean \& Green Program with vacant lots not in the program. We compared observations of visible features that could be found on vacant lots (discarded vehicles, discarded appliances and furniture, graffiti, fire damage, construction on site, and vegetable garden) and found very low base rates (less than $2 \%$ for all features) and no significant differences between the program and no-program vacant lots. We also compared the litter, trash, and mowing ratings for the two samples of vacant lots and found the Clean \& Green program lots had higher mowing ratings than the no-program lots $(F=18.04, p<.001)$. We found no significant difference, however, in the litter 
and trash ratings. The Lawn Maintenance scale also produced a predicted significant difference between the two samples of vacant lots $(F=4.49, p<.05)$.

\section{DISCUSSION}

Our results indicate the PMOT is a psychometrically sound measure of physical disorder on individual property parcels. This observational assessment protocol affords researchers the ability to assess the physical disorder at the most specific recorded geographical unit of analysis. Because of this geographic specificity, the PMOT may allow for the study of microgeographies that help to more richly contextualize and inform our understanding of the effects of neighborhood features on health and crime. In this manner, such microgeographic assessment can be used in combination with a myriad of other data, such as subjective neighborhood assessment, activity space measures and crime data to examine pressing public health, policing, and policy. The PMOT's specificity may also prove useful to practitioners evaluating the effects of property maintenance programs because the assessment protocol can account for the variation in owners' maintenance of parcels.

After 6 hours of training and after reviewing initial reliability tests, the trained observers achieved a high rate of agreement, with standard observations identifying the type of parcel, identifying visible features of physical disorder and order, and rating the maintenance of buildings and grounds. The observers' reliability increased slightly after reviewing initial reliability tests during a follow-up training. The high rates of agreement are especially impressive given the low base rates of these visible features on the observed parcels.

The visible features included in the PMOT are relatively easy to discern for the observers, perhaps because the features are well defined and easy to see from standing in front of the parcel. The high agreement with standard observations may also be due to the ease of using dichotomous measures of these visible features. The correlations with standard observations for the multipoint ratings of building maintenance were high after the initial training sessions and improved slightly after the follow-up training. The follow-up training, however, was necessary to improve the reliability statistics for rating the landscaping and the mowing/weeding. The observers' reliability of rating the amount of litter and trash on the parcels remained relatively low even after the follow-up training. Judging the total volume of litter and trash may be difficult because litter and trash are dispersed over an entire parcel. The observer must judge the volume of the dispersed litter and trash if it were gathered together in one place.

This study also documents the base rates for PMOT measures and the correlations among PMOT measures for two primarily residential neighborhoods in a lower income urban setting. We recommended a set of internally consistent multi-item measurement scales that combine highly correlated PMOT measures. These results may be most useful for researchers and practitioners working in low-income, residential neighborhoods. Those who are interested in understanding or improving features of physical disorder and order for other types of neighborhoods may need to generate their own measurement base rates.

The results of this study provide preliminary evidence of the concurrent validity of the PMOT measures. The validity analyses confirm our hypothesis that the PMOT measures of parcel maintenance were much higher for parcels with occupied buildings than for parcels with unoccupied buildings. The measured differences are strong for visible features of physical disorder even though we noted low base rates for many of these features. The 
hypothesized differences for the parcel ratings are also strongly supported even though some of these measures had low inter-rater reliability.

The predicted difference in the lawn maintenance ratings between vacant lots in the Clean \& Green program and vacant lots not in the program provides further support for the validity of those PMOT measures. In particular, the observers' ratings of regular mowing distinguished the two samples of parcels. For the parcels in this study, the PMOT rating for the volume of litter and trash is not effective in distinguishing the Clean \& Green program lots from the no-program lots. It is possible this lack of difference in the litter and trash rating was due to factors outside of the Clean \& Green program's control. The Clean \& Green program staff explained to us that the litter and trash on the program lots reflected a city policy that limited trash pick-up on vacant lots in Flint during the time of this study.

\section{Limitations}

A few limitations of this study are important to consider. Although the PMOT was designed for measuring physical disorder in urban settings, it is important to replicate these results in other types of neighborhood settings, especially neighborhoods that differ in function (e.g., commercial neighborhoods) and economic status. The PMOT may also need to be adapted if used in rural and suburban settings to assess all maintenance and disorder features unique to those settings such as fences, farm buildings, and wooded areas.

\section{Conclusion}

These limitations notwithstanding, our results suggest the PMOT can be a useful measure for assessing features of physical disorder on individual parcels. The PMOT also includes assessments not used in previously published measures of physical disorder on parcels such as fire damage, discarded appliances, building structural elements, and landscaping maintenance. Assessing disorder on parcels allows the option of testing hypotheses regarding parcel-level disorder or aggregating parcel-level data to test hypotheses about disorder for larger geographic units such as street segments, block groups, or defined neighborhood areas. The PMOT could be used to evaluate neighborhood improvement programs directed at improving the physical features of parcels.

The PMOT could also be used to study how features of neighborhood disorder are prospectively related to health outcomes and crime rates within a variety of defined geographic areas. With the ability to account for variation among property parcels, the PMOT researcher could study the radiating effects of physical disorder over time. This more spatial understanding of adjacency allows for a more dynamic and realistic assessment of neighborhoods. Finally, the PMOT could be used to study the spatial and temporal correlations between features of neighborhood disorder and a variety of health and crime outcomes. Measuring specific features of physical disorder and property maintenance at the parcel level provides greater methodological possibilities for understanding how neighborhoods may influence and improve the health and safety of residents.

\section{REFERENCES}

Auchincloss, A., Diez Roux, A., Brown, D., Erdmann, C., \& Bertoni, A. (2008). Neighborhood resources for physical activity and healthy foods and their association with insulin resistance. Epidemiology, 19, 146-157. 
Barker, R. (1968). Ecological psychology. Stanford, CA: Stanford University Press.

Bethell, T. (1998). The noblest triumph: Property and prosperity through the ages. New York: St. Martin's Press.

Brantingham, P., \& Brantingham, P. (1999). Theoretical model of crime hot spot generation. Studies on Crime and Crime Prevention, 8, 7-26.

Brown, B., Perkins, D., \& Brown, G. (2004). Incivilities, place attachment and crime: Block and individual effects. Journal of Environmental Psychology, 24, 359-371.

Bursik, R., \& Grasmick, H. (1993). Neighborhoods and crime. San Francisco: Lexington.

Cronbach, L., \& Meehl, P. (1955). Construct validity in psychological tests. Psychological Bulletin, 52, 281-302.

Diez Roux, A., \& Mair, C. (2010). Neighborhoods and health. Annals of the New York Academy of Sciences, 1186, 125-145.

Dupere, V., \& Perkins, D. (2007). Community types and mental health: A multilevel study of local environmental stress and coping. American Journal of Community Psychology, 39, 107-119.

Eck, J., \& Weisburd, D. (1995). Crime places in crime theory. Monsey, NY: Willow Tree Press.

Furr-Holden, C., Campbell, K., Milam, A., Smart, M., Ialongo, N., \& Leaf, P. (2010). Metric properties of the neighborhood inventory for environmental typology (NIfETy): An environmental assessment tool for measuring indicators of violence, alcohol, tobacco, and other drug exposures. Evaluation Review, 34, 159-184.

Furr-Holden, C., Smart, M., Pokorni, J., Ialongo, N., Leaf, P., Holder, H., \& Anthony, J. (2008). The NIfETy method for environmental assessment of neighborhood-level indicators of violence, alcohol and other drug exposure. Prevention Science, 9, 245-255.

Kornhauser, R. (1978). Social sources of delinquency. Chicago: University of Chicago Press.

Larson, N., Story, M., \& Nelson, M. (2009). Neighborhood environments: disparities in access to healthy foods in the U.S. American Journal of Preventative Medicine, 36, 74-81.

Latkin, C., \& Curry, A. (2003). Stressful neighborhoods and depression: a prospective study of the impact of neighborhood disorder. Journal of Health and Social Behavior, 44, 34-44.

Mair, C., Diez Roux, A., \& Galea, S. (2008). Are neighbourhood characteristics associated with depressive symptoms? A review of evidence. Journal of Epidemiology and Community Health, 62, 940-948.

Morgan, M., Morgan, S., \& Santos, R. (2013). City crime rankings 2013: Crime in metropolitan America. Thousand Oaks, CA: Sage Publications.

Morrel-Samuels, S., Zimmerman, M. A., Reischl, T. M (2013). Creating safe and healthy futures: Michigan youth violence prevention center. Reclaiming Children and Youth, 22(3), 31-36.

Mujahid, M., Diez Roux, A., Morenoff, J., \& Raghunathan, T. (2007). Assessing the measurement properties of neighborhood scales: From psychometrics to ecometrics. American Journal of Epidemiology, 165, 858-867.

Mujahid, M., Diez Roux, A., Morenoff, J., Raghunathan, T., Cooper, R., Ni, H., \& Shea, S. (2008). Neighborhood characteristics and hypertension. Epidemiology, 19, 590-598.

Natsuaki, M., Ge, X., Brody, G., Simons, R., Gibbons, F., \& Cutrona, C. (2007). African American children's depressive symptoms: The prospective effects of neighborhood disorder, stressful life events, and parenting. American Journal of Community Psychology, 39, 163-176.

Papas, M., Alberg, A., Ewing, R., Helzlsouer, K., Gary, T., \& Klassen, A. (2007). The built environment and obesity. Epidemiology, 29, 129-143.

Perkins, D. D., Meeks, J., \& Taylor, R. B. (1992). The physical environment of street blocks and resident perceptions of crime and disorder: Implications for theory and measurement. Journal of Environmental Psychology, 12, 21-34. 
Perkins, D. D., \& Taylor, R. B. (1996). Ecological assessments of community disorder: Their relationship to fear of crime and theoretical implications. American Journal of Community Psychology, 24, 63-107.

Perkins, D. D., Wandersman, A., Rich, R. C., \& Taylor, R. B. (1993). The physical environment of street crime: Defensible space, territoriality and incivilities. Journal of Environmental Psychology, 13, 29-49.

Pickett, K., \& Pearl, M. (2001). Multilevel analyses of neighbourhood socioeconomic context and health outcomes: A critical review. Journal of Epidemiology and Community Health, 55, $111-$ 122.

Raudenbush, S., \& Sampson, R. (1999). Assessing direct and indirect effects in multilevel designs with latent variables. Sociological Methods and Research, 28, 123-153.

Ross, C., \& Mirowsky, J. (2001). Neighborhood disadvantage, disorder, and health. Journal of Health and Social Behavior, 42, 258-276.

Saelens, B., \& Handy, S. (2008). Built environment correlates of walking: A review. Medicine \& Science in Sports \& Exercise, 40, S550-S566.

Sampson, R., \& Groves, W. (1989). Community structure and crime: Testing social-disorganization theory. American Journal of Sociology, 94, 774-802.

Sampson, R., Morenoff, J., \& Gannon-Rowley, T. (2002). Assessing "neighborhood effects": Social processes and new directions in research. Annual Review of Sociology, 28, 443-478.

Sampson, R., \& Raudenbush, S. (1999). Systematic social observation of public spaces: A new look at disorder in urban neighborhoods. American Journal of Sociology, 105, 603-651.

Sampson, R., Raudenbush, S., \& Earls, F. (1997). Neighborhoods and violent crime: A multilevel study of collective efficacy. Science, 277, 918-924.

Shaw, C., \& McKay, H. (1942). Juvenile delinquency and urban areas. Chicago: University of Chicago Press.

Sherman, L., Gartin, P., \& Buerger, M. (1989). Hot spots of predatory crime: Routine activities and the criminology of place. Criminology, 27, 27-56.

Spelman, W. (1995). Criminal careers of public places. In J. Eck \& D. Weisburd (Eds.), Crime and place: Crime prevention studies (pp. 115-144). Monsey, NY: Willow Tree Press.

Taylor, R. (1997). Social order and disorder of street blocks and neighborhoods: Ecology, microecology, and the systemic model of social disorganization. Journal of Research in Crime and Delinquency, 34, 113-155.

U.S. Bureau of Labor Statistics. (2013). Unemployment rates for metropolitan areas. Retrieved from http://www.bls.gov/web/metro/laummtrk.htm

U.S. Census Bureau. (2013). State \& county quick facts: Flint (city), Michigan. Retrieved from http:/ quickfacts.census.gov/qfd/states/26/2629000.html

Warner, B., \& Rountree, P. (1997). Local social ties in a community and crime model: Questioning the systemic nature of informal social control. Social Problems, 44, 520-536.

Weisburd, D., Bushway, S., Lum, C., \& Yang, S. (2004). Trajectories of crime at places: A longitudinal study of street segments in the city of Seattle. Criminology, 42, 283-321.

Weisburd, D., \& Green, L. (1994). Defining the drug market: The case of the Jersey City DMAP system. In D. L. MacKenzie \& C. D. Uchida (Eds.), Drugs and crime: Evaluating public policy initiatives (pp. 61-76). Newbury Park, CA: Sage Publications.

Weisburd, D., \& Green, L. (2000). Crime and disorder in drug hot spots: Implications for theory and practice in policing. Police Quarterly, 3, 152-170. 